\title{
Patient preferences on rheumatoid arthritis second-line treatment: a discrete choice experiment of Swedish patients
}

\author{
Karin Schölin Bywall ${ }^{1 *} \mathbb{D}$, Ulrik Kihlbom ${ }^{1}$, Mats Hansson ${ }^{1}$, Marie Falahee ${ }^{2}$, Karim Raza ${ }^{2,3}$, Eva Baecklund ${ }^{4}$ and \\ Jorien Veldwijk ${ }^{5}$
}

\begin{abstract}
Background: Preference assessments of patients with rheumatoid arthritis can support clinical therapeutic decisions for including biologic and targeted synthetic medicines to use. This study assesses patient preferences for attributes of second-line therapies and heterogeneity within these preferences to estimate the relative importance of treatment characteristics and to calculate the minimum benefit levels patients require to accept higher levels of side effects.

Methods: Between November 2018 to August 2019, patients with rheumatoid arthritis were recruited to a survey containing demographic and disease-related questions as well as a discrete choice experiment to measure their preferences for second-line therapies using biologics or Janus kinases inhibitors. Treatment characteristics included were route of administration, frequency of use, probability of mild short-term side effects, probability of side effects changing appearance, probability of psychological side effects, probability of severe side effects and effectiveness of treatment.
\end{abstract}

Results: A total of 358 patients were included in the analysis. A latent class analysis revealed three preference patterns: (1) treatment effectiveness as the single most important attribute, (2) route of administration as the most important attribute, closely followed by frequency of use and psychological side effects and (3) severe side effects as the most important attribute followed by psychological side effects. In addition, disease duration and mild side effects influenced the patients' choices.

Conclusion: Respondents found either effectiveness, route of administration or severe side effects as the most important attribute. Patients noting effectiveness as most important were more willing than other patients to accept higher risks of side effects.

Keywords: Discrete choice experiment, Patient preferences, Rheumatoid arthritis, Second-line treatment

\footnotetext{
* Correspondence: Karin.bywall@crb.uu.se

${ }^{1}$ Centre for Research Ethics \& Bioethics, Department of Public Health and Caring Sciences, Uppsala University, Husargatan 3, Box 564, 75237 Uppsala, Sweden

Full list of author information is available at the end of the article
}

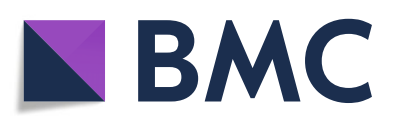

(- The Author(s). 2020 Open Access This article is licensed under a Creative Commons Attribution 4.0 International License, which permits use, sharing, adaptation, distribution and reproduction in any medium or format, as long as you give appropriate credit to the original author(s) and the source, provide a link to the Creative Commons licence, and indicate if changes were made. The images or other third party material in this article are included in the article's Creative Commons licence, unless indicated otherwise in a credit line to the material. If material is not included in the article's Creative Commons licence and your intended use is not permitted by statutory regulation or exceeds the permitted use, you will need to obtain permission directly from the copyright holder. To view a copy of this licence, visit http://creativecommons.org/licenses/by/4.0/. The Creative Commons Public Domain Dedication waiver (http://creativecommons.org/publicdomain/zero/1.0/) applies to the data made available in this article, unless otherwise stated in a credit line to the data. 


\section{Key points}

- Patients with rheumatoid arthritis found either effectiveness of treatment, route of administration or probability of severe side effects to be the most important treatment attribute.

- Patients identifying effectiveness as most important were more willing than other patients to accept higher risks of side effects.

- This study could support shared decision-making by recognising the different preference patterns of patients.

- Results from this study have the potential to support regulatory marketing authorisations of rheumatoid arthritis treatments by revealing the minimum acceptable benefit levels required to compensate respondents for worsening levels of side effects.

\section{Introduction}

Information about patient preferences has long been considered important for supporting patient-centeredness in clinical decisions [1]. Over the past decade, measuring patient preferences has evolved to use methods that quantify preferences in the clinical context [2-5]; these approaches have more recently also been used in rheumatology [6]. Recently, the interest in quantifying treatment preferences of patients with rheumatic diseases has been expanded to regulatory marketing authorisation decisions of new rheumatic disease medicines $[7,8]$. Quantitative assessments of patient preferences may be important in regulatory marketing approvals in order to adjust decisionmaking to patient opinions on the meaning and significance of treatment attributes, such as the balance between estimated effects and adverse reactions $[9,10]$. A better adjustment to patient preferences may also have a positive impact on patient adherence [9].

Patients with rheumatoid arthritis (RA) are often treated with multiple disease-modifying anti-rheumatic drugs (DMARD). DMARDs have different modes of action and characteristics, such as method and frequency of administration and probability of adverse events or monitoring requirements. Newly diagnosed patients with RA usually start with conventional synthetic DMARDs as first-line therapy. If first-line therapy is not tolerated or is ineffective, biologics or Janus kinases (JAK) inhibitors are recommended [11]. A potential advantage of JAK inhibitors is that they are given orally rather than subcutaneously or intravenously as is required for biologics [12].

Previous research has shown that cost, efficacy, and administration strongly influence patient preferences for second-line therapy-i.e., biologics or JAK inhibitors $[2,3,13]$. However, both biologics and JAK inhibitors are associated with side effects such as infections, increased blood and cholesterol levels, nausea, anxiety, and skin rash [12]. Therefore, clinicians should provide patients with specific information about treatments with these medicines, including the extent and probability of experiencing side effects. Although treatment costs can be an important determinant of preference, they are less relevant in countries with universal health care systems, as is the case for most of Europe.

Clinicians need to understand their patients' preferences and perspectives when informing them about potential RA treatments so their patients can influence decisions about their treatment to align with their preferences $[9,10,14]$. Quantitative assessments of patient preferences have the potential to support both clinicians and regulators when they consider patient perspectives $[7,12]$. Currently there is a lack of evidence about the extent to which patients feel that risks of side effects would be acceptable for new second-line treatments. This study assesses preferences regarding attributes of second-line treatments and heterogeneity within these preferences for patients with RA. These preferences are used to estimate the relative importance of different treatment characteristics and to calculate the minimum benefit levels patient require in order to accept higher levels of potential side effects.

\section{Methods}

\section{Recruitment}

Treatment preferences of patients with RA were assessed using a discrete choice experiment (DCE). An invitation to participate in the study was advertised to members of the Swedish Rheumatism Association via email, newspaper, newsletter, social media, mobile application, and the association's website. The invitation to participate was also distributed to patients attending ten rheumatology clinics in Sweden and via an online research panel of patients with RA. A printed copy of the survey was distributed by the Rheumatology clinic at Uppsala University hospital. All participants received information about the study and provided their informed consent before completing the survey. The following inclusion criteria were used: established RA diagnosis, $18-80$ years of age, and the ability to understand and answer the questions. Data were collected from November 2018 to August 2019. The survey was approved by the regional ethics review board in Uppsala, Sweden (Reg no. 2017/ 521, 2018/156). Data generation, storage and sharing were governed by the General Data Protection Regulation (GDPR) Act, Uppsala University data protection and security policies, and ethical consent provided.

\section{Methodology of discrete choice experiment}

DCE, a cross-sectional survey method used to assess preferences, allows for quantitative assessment of patient 
preferences for health care policies, services, and interventions [15]. DCE, which uses random utility theory (RUT), aims to quantify the relative importance of one treatment characteristic over another treatment characteristic. RUT assumes that the value (utility) of a product can be determined by the value (utility) of the characteristics of that product (i.e., attributes) and their levels. Respondents in a DCE are presented with hypothetical scenarios (choice questions) with varying attributes and levels. Respondents are asked to choose their preferred option for each question [16]. The utility can be estimated by modelling the choices that respondents make between alternatives of treatments that are described by different choice questions [17]. DCEs can also be used to measure and explain heterogeneity within the preferences of patients [18].

\section{Attributes and levels}

Using a step-wise approach, we identified attributes and levels for inclusion in the DCE. First, the analysis of a literature review of previous studies of patient preferences for DMARDs resulted in 12 potential treatment attributes $[2,3,5,14,19-24]$. Second, the attributes and levels identified in the literature review were discussed with a rheumatologist to make sure that they reflected current clinical practice. Third, three focus groups using the nominal group technique (NGT) were conducted with patients with RA $(n=7)$; these patients were asked to identify new attributes and rank all potential attributes from most to least important [25]. The focus groups were audio recorded, lasted for about $90 \mathrm{~min}$, and conducted using an interview guide. Fourth, results from the focus groups were discussed during several validation meetings with one rheumatologist, the research team, and two patient research partners. These meetings revealed seven attributes: route of administration, frequency of use, probability of mild short-term side effects, probability of side effects changing appearance, probability of psychological side effects, probability of severe side effects, and effectiveness of treatment. Each attribute was revealed to have three levels based on current clinical knowledge of existing biologics and JAK inhibitors. Detailed information regarding the selection and description of the attributes and levels is available in the Supplementary material. All attributes and levels included in the DCE are displayed in Table 1.

\section{Experimental design and survey}

The survey started with information about RA and available treatment options before entering the DCE. The last section of the survey consisted of demographic and disease-related questions, health literacy [26], and numeracy [27]. The DCE had an attribute-based experimental design. Respondents were asked to choose their preferred treatment from two alternatives (see Fig. 1, example of a choice question). The choice questions also included a hover function with further explanations of the attributes and the levels (see Supplementary file for full text explanations of attributes and levels).

The survey was pilot tested with a subgroup $(n=22)$ of patients with RA and patient research partners. Six of the pilot tests were 'think aloud' interviews. The respondents were encouraged to articulate their thoughts while completing the survey. The language and the layout of the survey were slightly changed after the pilot test. Using the pilot test data, we fitted a multinomial logit (MNL) model and used the beta estimates as priors for the final experimental DCE design generated by NGene 1.0 (ChoiceMetrics, 2011), which is a $d$ efficient (Bayesian) design [28]. A constraint was posed on the design: route of administration and frequency of use (e.g., if the route of administration was a tablet, the frequency of use could not be 'monthly'). A total of 60 unique choice questions were divided into four blocks. Each respondent had to answer 15 unique choice questions. All attributes were displayed in each of the choice questions; three attributes were identical across the two offered alternatives to reduce the cognitive burden to respondents. We applied the decision-making scenario 'think of yourself in a situation where your treatment is not working, your joints are swollen, you have pain or unbearable side effects and need to change to a second-line treatment'.

\section{Statistical analysis}

SPSS $^{\bullet}$ Statistics 20 and Nlogit ${ }^{\bullet}$ were used for analyses. Demographic data were analysed using descriptive statistics. Results were considered statistically significant if $P<0.05$. The patients' preferences were determined by attribute level estimates using a MNL model [29]. Latent class analysis (LCA) models were used for further analysis of the DCE data. Such models account for the multilevel structure of the data (i.e., every respondent answered multiple choice questions) and account for the investigation of preference heterogeneity. LCA models assume that there are two or more latent classes of data with different preferences. The classes are characterised by unobserved latent variables that can be related to a set of choice patterns. Once choice patterns have been stratified into classes, it is possible for the model to determine the probability that a respondent with certain characteristics will be assigned to each class [30]. The attributes were dummy coded (i.e., the mean effect for each attribute was normalised at zero) except for effectiveness that was effects-coded. The 'likelihood ratio test' and the Akaike information criterion (AIC) were used to determine the most appropriate model. A three-class model based on the utility is displayed below: 
Table 1 Attributes and levels

\begin{tabular}{|c|c|c|c|}
\hline Attribute & Level 1 & Level 2 & Level 3 \\
\hline Route of administration & Tablet & Injection & Drip \\
\hline Frequency of use & Daily & Weekly & Monthly \\
\hline $\begin{array}{l}\text { Probability of mild short-term side } \\
\text { effects (nausea, vomiting or } \\
\text { headache) }\end{array}$ & Common 1 in 10 & Uncommon 1 in 100 & Rare 1 in 1000 \\
\hline $\begin{array}{l}\text { Probability of side effects changing } \\
\text { appearance (hair loss, weight } \\
\text { changes or skin rash) }\end{array}$ & Common 1 in 10 & Uncommon 1 in 100 & Rare 1 in 1000 \\
\hline $\begin{array}{l}\text { Probability of psychological side } \\
\text { effects (anxiety, mood changes, } \\
\text { depression or sleep disturbance) }\end{array}$ & Common 1 in 10 & Uncommon 1 in 100 & Rare 1 in 1000 \\
\hline $\begin{array}{l}\text { Probability of severe side effects that } \\
\text { requires hospitalisation such as } \\
\text { severe infections or allergic reactions }\end{array}$ & Common 1 in 10 & Uncommon 1 in 100 & Rare 1 in 1000 \\
\hline $\begin{array}{l}\text { Effectiveness (the ability to decrease } \\
\text { inflammation and swelling of the } \\
\text { joints, also pain and other } \\
\text { symptoms) }\end{array}$ & $\begin{array}{l}30 \% \text { improvement. So out of } \\
100 \text { persons taking the } \\
\text { treatment, } 30 \text { will get enough } \\
\text { improvement; the rest will get } \\
\text { a small or no improvement }\end{array}$ & $\begin{array}{l}50 \% \text { improvement. So out of } \\
100 \text { persons taking the } \\
\text { treatment, } 50 \text { will get enough } \\
\text { improvement; the rest will get } \\
\text { a small or no improvement }\end{array}$ & $\begin{array}{l}70 \% \text { improvement. So out of } \\
100 \text { persons taking the } \\
\text { treatment, } 70 \text { will get enough } \\
\text { improvement; the rest will get } \\
\text { a small or no improvement }\end{array}$ \\
\hline
\end{tabular}

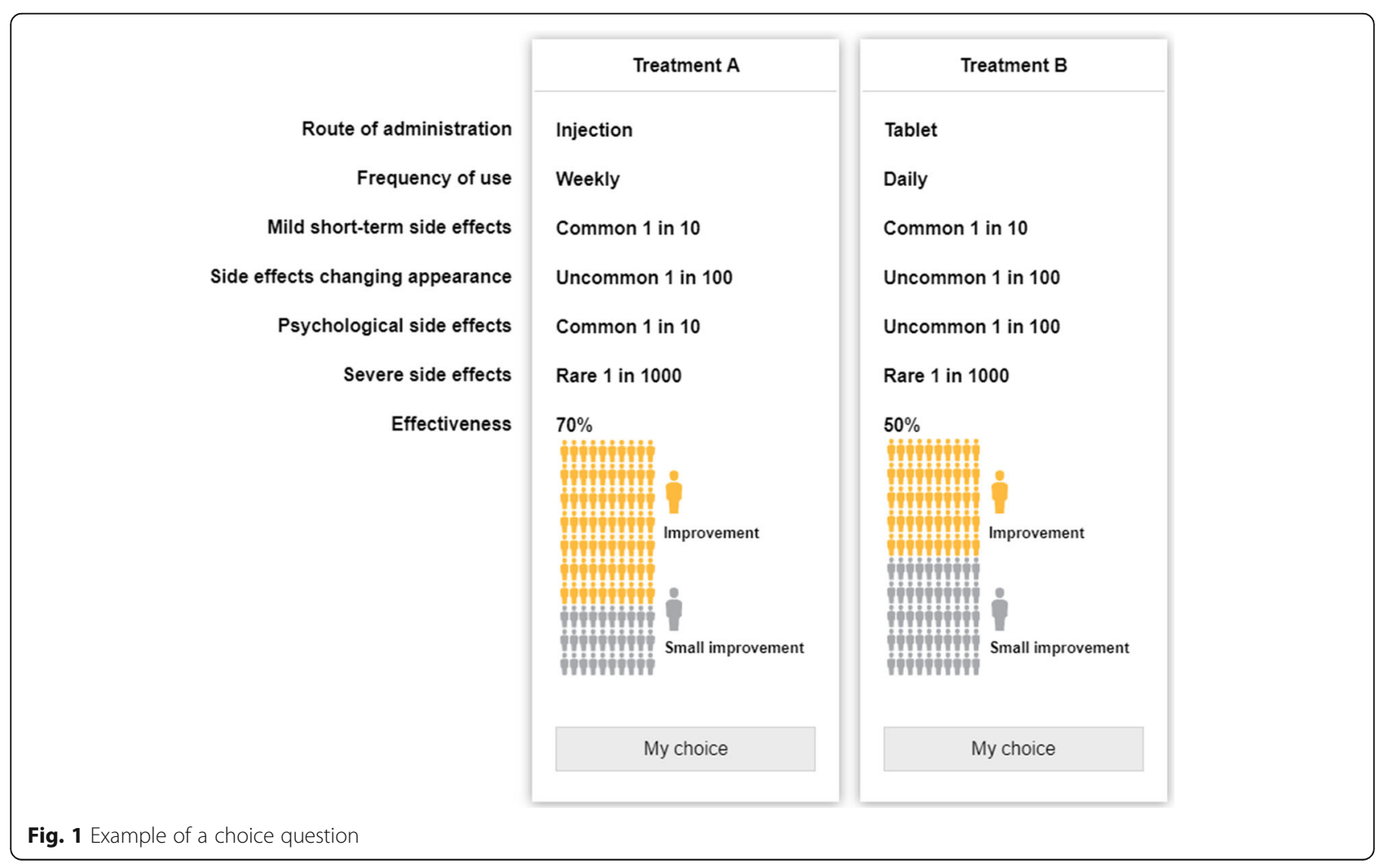




$$
\begin{aligned}
& V_{r t a \mid c}=\beta_{1 \mid c} \text { Route of administration }{ }_{\text {Tablet } r t a \mid c} \\
& +\beta_{2 \mid c} \text { Route of administration }{ }_{\text {Injection } r t a \mid c} \\
& +\beta_{3 \mid c} \text { Frequency of use } e_{\text {Daily } r t a \mid c} \\
& +\beta_{4 \mid c} \text { Frequency of use Weekly } r t a \mid c \\
& +\beta_{5 \mid c} \text { Mild short - term side ef fects } 1_{1} \text { in } 10 \mathrm{rta|c} \\
& +\beta_{6 \mid c} \text { Mild short - term side ef fects } 1 \text { in } 100 \text { rta|c } \\
& +\beta_{7 \mid c} \text { Appearance side ef fects }{ }_{1} \text { in } 10 \mathrm{rta|c} \\
& +\beta_{8 \mid c} \text { Appearance side ef fects } \mathrm{fin}_{1} 100 \mathrm{rta|c} \\
& +\beta_{9 \mid c} \text { Psychological side ef fects } \mathrm{fin}_{10} 10 \mathrm{rta|c} \\
& +\beta_{10 \mid c} \text { Psychological side ef fects } 1 \text { in } 100 \mathrm{rta|c} \\
& +\beta_{11 \mid c} \text { Severe side ef fects }{ }_{1 \text { in } 10} \mathrm{rta|c} \\
& +\beta_{12 \mid c} \text { Severe side ef fects } 1 \text { in } 100 \mathrm{rta|c} \\
& +\beta_{13 \mid c} \text { Effectiveness } r t a \mid c
\end{aligned}
$$

The utility component $(V)$ describes the utility that respondent ' $r$ ' belonging to class ' $c$ ' reported for alternative ' $a$ ' in choice question ' $t$ '. The attribute level estimates of each attribute level are represented by $\beta_{1}-\beta_{13}$. A class assignment model was fitted after the specified utility function. Several demographic and disease-related variables were tested for their potential impact on class membership in the LCA: age, gender, numeracy, health literacy, education level, disease duration, occupational status, and experience with DMARD treatment and side effects. The final class assignment utility function was:

$$
\begin{aligned}
V_{\mathrm{rc}}= & \beta_{1 \mid c} \text { disease duration } \\
& +\beta_{2 \mid c} \text { and mild side effects } r
\end{aligned}
$$

A significant attribute estimate within a certain class indicates that this attribute contributes to the decisionmaking process of respondents who belong to that class. The sign of the beta indicates whether the attribute level has a positive or negative effect on the utility.

To calculate the relative importance of the attributes, the difference between the highest and lowest estimates of the attribute level was calculated for each attribute. The largest difference value was given a 1 , representing the attribute that was deemed most important by respondents. The other difference values were divided by the largest difference value, resulting in a relative distance between all other attributes and the most important attribute.

A minimum acceptable benefit (MAB) for changes in attribute levels was calculated. The MAB is interpreted as the minimum change in effectiveness that respondents would require (on average) to accept changes to a less desirable level in another attribute (probability of getting a certain side effect by $10 \%, 1 \%$, and $0.1 \%$ ). MAB was estimated as the difference between the preference weights (parameters) for two levels ' $l$ ' of an attribute divided by the preference weight, $\beta_{k=\text { effectiveness, which is }}$ the unit change in the level of benefit:

$$
\mathrm{MAB}=-\frac{\left(\beta_{k, l=2}-\beta_{k, l=1}\right)}{\left(\beta_{k=\text { effectiveness },}\right)}
$$

\section{Results \\ Respondents}

In total, 422 patients completed the full survey although 29 were removed after testing for flat-lining (choosing option A at least 13 out of 15 times) and 35 were removed because they answered the survey in under 5 min. Most of the respondents were female (77\%). The respondents represented all age categories between 18 and 80 years of age. The level of education was categorised into low $(n=105)$, medium $(n=86)$, or high $(n=$ 162). A full overview of patient and disease characteristics is presented in Table 2.

\section{Preferences and relative importance}

The multinomial logit model revealed that all of the attribute estimates significantly contributed to the decision-making process of respondents. The sign of the beta indicates whether the attribute level has a positive or negative effect on the utility. On average, respondents preferred a tablet and injection over a drip (as indicated by the positive estimates for tablet and injection). The respondents also preferred monthly over weekly or daily medication. A strong disutility for the highest frequency of side effects was found in all classes. Finally, respondents preferred the medicine with the highest effectiveness. The directions of the effects of the attributes on utility were as expected, which confirms that respondents understood the choice questions. On average, the most important attribute for respondents was the probability of severe side effects. Treatment effectiveness was the second most important attribute, closely followed by the probability of psychological side effects. Route of administration came in fourth place followed by frequency of use, probability of mild short-term side effects, and side effects changing appearance.

\section{Preference heterogeneity}

Considerable heterogeneity was found in the preferences, as can be seen in the three classes representing differences in preferences in Table 3. The average probability of respondents belonging to one of the classes was $34 \%, 28 \%$, and $38 \%$, respectively. The model fit significantly improved when including disease duration and experience of mild short-term side effects (loglikelihod = 2495 - and $-2491, P<0.05)$ to the class assignment model. 
Table 2 Patient and disease characteristics

\begin{tabular}{|c|c|c|}
\hline Item & $N$ & $N$ in $\%$ \\
\hline Total & 358 & 100 \\
\hline \multicolumn{3}{|l|}{ Gender } \\
\hline Female & 272 & 77 \\
\hline Male & 83 & 23 \\
\hline \multicolumn{3}{|l|}{ Age } \\
\hline $18-24$ & 15 & 4 \\
\hline $25-34$ & 42 & 12 \\
\hline $35-44$ & 31 & 9 \\
\hline $45-54$ & 64 & 18 \\
\hline $55-64$ & 99 & 28 \\
\hline $65-80$ & 105 & 30 \\
\hline \multicolumn{3}{|l|}{ Education level } \\
\hline $\begin{array}{l}\text { Low (elementary school, primary school, } \\
\text { real school or similar, 2-year high school } \\
\text { or vocational school, 3-4 year high school) }\end{array}$ & 105 & 30 \\
\hline Medium (college or university shorter than 3 years) & 89 & 25 \\
\hline High (college or university 3 years or longer) & 162 & 45 \\
\hline \multicolumn{3}{|l|}{ Occupational status } \\
\hline $\begin{array}{l}\text { Full time employee, part time employee, parental } \\
\text { leave/occupational leave }\end{array}$ & 154 & 43 \\
\hline $\begin{array}{l}\text { Work part time since RA, long-term sick leave, } \\
\text { sick pension }\end{array}$ & 79 & 22 \\
\hline Age pensioner/unemployed & 177 & 33 \\
\hline Other & 6 & 2 \\
\hline \multicolumn{3}{|l|}{ Health literacy } \\
\hline Sufficient & 197 & 55 \\
\hline Problematic & 134 & 38 \\
\hline Lacking & 24 & 7 \\
\hline \multicolumn{3}{|l|}{ Numeracy } \\
\hline High & 28 & 8 \\
\hline Medium & 212 & 60 \\
\hline Low & 113 & 32 \\
\hline \multicolumn{3}{|l|}{ Disease duration } \\
\hline $1-12$ months & 22 & 6 \\
\hline $1-5$ years & 88 & 25 \\
\hline $5-10$ years & 67 & 19 \\
\hline More than 10 years & 179 & 50 \\
\hline \multicolumn{3}{|l|}{ Time till onset of drug effect } \\
\hline $0-3$ months & 121 & 34 \\
\hline 3-12 months & 87 & 25 \\
\hline $1-2$ years & 33 & 9 \\
\hline $2-5$ years & 37 & 11 \\
\hline More than 5 years & 32 & 9 \\
\hline Still not working & 43 & 12 \\
\hline
\end{tabular}

Table 2 Patient and disease characteristics (Continued)

\begin{tabular}{lll}
\hline Item & $\boldsymbol{N}$ & $\boldsymbol{N}$ in \% \\
\hline Experience with treatment & & \\
First line treatment only (csDMARDs) & 182 & 51 \\
Second line treatment, biologics & 116 & 32 \\
JAK inhibitors & 12 & 3 \\
Experience with side effects & & \\
Mild short term & 205 & 57 \\
Appearance & 154 & 43 \\
Psychological & 137 & 38 \\
Severe & 80 & 22 \\
No side effects & 89 & 24 \\
\hline
\end{tabular}

Although the directions of the impact of the attribute levels on utility were the same in all classes, high levels of heterogeneity were observed with respect to the importance of the attribute levels. The relative importance (RI) score of the attributes was separately calculated for the three classes of the latent class analysis (Fig. 1). According to class 1 , treatment effectiveness was the single most important attribute. While in class 2 , route of administration was the most important attribute, closely followed by frequency of use and psychological side effects. Severe side effects were the most important attribute followed by psychological side effects for class 3 . Respondents with newly diagnosed RA and no experiences of mild short-term side effects were more likely to belong to class 2 , whereas respondents with longer disease duration and previous mild short-term side effects were more likely to belong to class 3 (Fig. 2).

\section{Minimum acceptable benefit}

Table 4 shows the minimum acceptable benefit (MAB) levels required (in percentage point increases in effectiveness) to compensate respondents for worsening levels of probability of certain side effects. Due to preference heterogeneity, large differences were found in the MAB across the three classes. In class 1 , only a small benefit was needed to accept a switch to a less favourable frequency of side effects. In the other two classes, respondents would require a larger increase in effectiveness to accept an increase in risk of side effects. The highest MAB levels were seen in class 3 respondents for moving from a $0.1 \%$ probability of severe side effects to a $10 \%$ probability, which required a 91.3 percentage point increase in treatment effectiveness. The second highest MAB level was seen in class 2 for moving from a $0.1 \%$ probability of psychological side effects to a $10 \%$ probability, which required a 75.0 percentage point increase in treatment effectiveness. 
Table 3 Preferences of patients based on latent class analysis

\begin{tabular}{|c|c|c|c|c|c|c|c|c|c|}
\hline & Class 1 estimate & SE & $\mathbf{R I}$ & Class 2 estimate & SE & $\mathbf{R I}$ & Class 3 estimate & SE & RI \\
\hline \multicolumn{10}{|l|}{ Route of administration } \\
\hline Tablet & $1.22^{* * *}$ & 0.27 & 0.25 & $0.92^{* * *}$ & 0.20 & 1.00 & $1.14^{* * *}$ & 0.19 & 0.31 \\
\hline Injection & $0.37^{* *}$ & 0.17 & & $0.51^{* * *}$ & 0.15 & & $0.64^{* * *}$ & 0.16 & \\
\hline \multicolumn{10}{|l|}{ Drip (ref) } \\
\hline \multicolumn{10}{|l|}{ Frequency of use } \\
\hline 1 a day & $-1.00^{* * *}$ & 0.18 & 0.22 & $-0.75^{* * *}$ & 0.16 & 0.82 & $-0.59^{* * *}$ & 0.14 & 0.16 \\
\hline 1 a week & $-0.47^{* * *}$ & 0.17 & & -0.23 & 0.14 & & -0.02 & 0.16 & \\
\hline \multicolumn{10}{|l|}{1 a month (ref) } \\
\hline \multicolumn{10}{|c|}{ Probability of mild short-term side effects } \\
\hline 1 in 10 & $-0.30^{*}$ & 0.17 & 0.06 & $-0.27^{*}$ & 0.14 & 0.29 & $-0.44^{* *}$ & 0.17 & 0.12 \\
\hline 1 in 100 & -0.15 & 0.13 & & -0.08 & 0.12 & & -0.06 & 0.14 & \\
\hline \multicolumn{10}{|l|}{1 in 1000 (ref) } \\
\hline \multicolumn{10}{|c|}{ Probability of side effects changing appearance } \\
\hline 1 in 10 & $-0.87^{* * *}$ & 0.20 & 0.18 & $-0.34^{* *}$ & 0.16 & 0.11 & $-1.55^{* * *}$ & 0.21 & 0.42 \\
\hline 1 in 100 & -0.04 & 0.17 & & -0.10 & 0.14 & & $-0.48^{* * *}$ & 0.15 & \\
\hline \multicolumn{10}{|l|}{1 in 1000 (ref) } \\
\hline \multicolumn{10}{|l|}{ Probability of psychological side effects } \\
\hline 1 in 10 & $-1.11^{* * *}$ & 0.23 & 0.23 & $-0.75^{* * *}$ & 0.18 & 0.82 & $-2.61^{* * *}$ & 0.28 & 0.72 \\
\hline 1 in 100 & -0.01 & 0.18 & & $-0.62^{* * *}$ & 0.15 & & $-0.34^{* *}$ & 0.17 & \\
\hline \multicolumn{10}{|l|}{1 in 1000 (ref) } \\
\hline \multicolumn{10}{|l|}{ Probability of severe side effects } \\
\hline 1 in 10 & $-1.75^{* * *}$ & 0.27 & 0.36 & -0.21 & 0.18 & 0.23 & $-3.65^{* * *}$ & 0.39 & 1.00 \\
\hline 1 in 100 & $-0.82^{* * *}$ & 0.16 & & -0.08 & 0.12 & & $-0.79^{* * *}$ & 0.16 & \\
\hline \multicolumn{10}{|l|}{1 in 1000 (ref) } \\
\hline Effectiveness (linear) & $0.12^{* * *}$ & 0.01 & 1.00 & $0.01^{* *}$ & 0.00 & 0.43 & $0.04^{* * *}$ & 0.00 & 0.44 \\
\hline \multicolumn{10}{|l|}{ Class probability model } \\
\hline Constant & 1.32 & 0.96 & & $2.51^{* * *}$ & 0.96 & & - & - & \\
\hline Disease duration & -0.16 & 0.12 & & $-0.32^{* * *}$ & 0.12 & & - & - & \\
\hline Experience with mild side effects & -0.46 & 0.36 & & $-0.99^{* *}$ & 0.39 & & - & - & \\
\hline Average class probability & 0.34 & & & 0.28 & & & 0.38 & & \\
\hline
\end{tabular}

"***," " "**" and "**" indicate significance at $1 \%, 5 \%$, and 10\%, respectively. $R /$ relative importance

\section{Discussion}

This study assesses preferences regarding second-line treatment and heterogeneity within these preferences among patients with RA as well as estimates of the relative importance of different treatment characteristics. In addition, this study calculates the minimum benefit levels patients require in order to accept higher levels of potential side effects. Respondents found either effectiveness of treatment, route of administration, or probability of severe side effects to be most important. This study also reveals that disease duration and experience with mild side effects had an impact on patients' choices. For newly diagnosed patients with no experience of mild side effects, route of administration (with oral administration being most preferred) was the most important treatment attribute. This preference might be due to wanting a treatment that fits with current lifestyle, since taking a tablet is less invasive and more convenient than a selfadministered injection or having an infusion [23]. In addition, respondents might find it easier to understand the impact of route of administration on daily life, whereas relatively small changes in side effects may be more complicated to understand.

Findings from this study are in line with previous research reporting on different patterns of preferences of patients with RA, as the importance of effectiveness and severe side effects $[2,3,13]$. However, the attributes and levels for this study address more side effects in the 


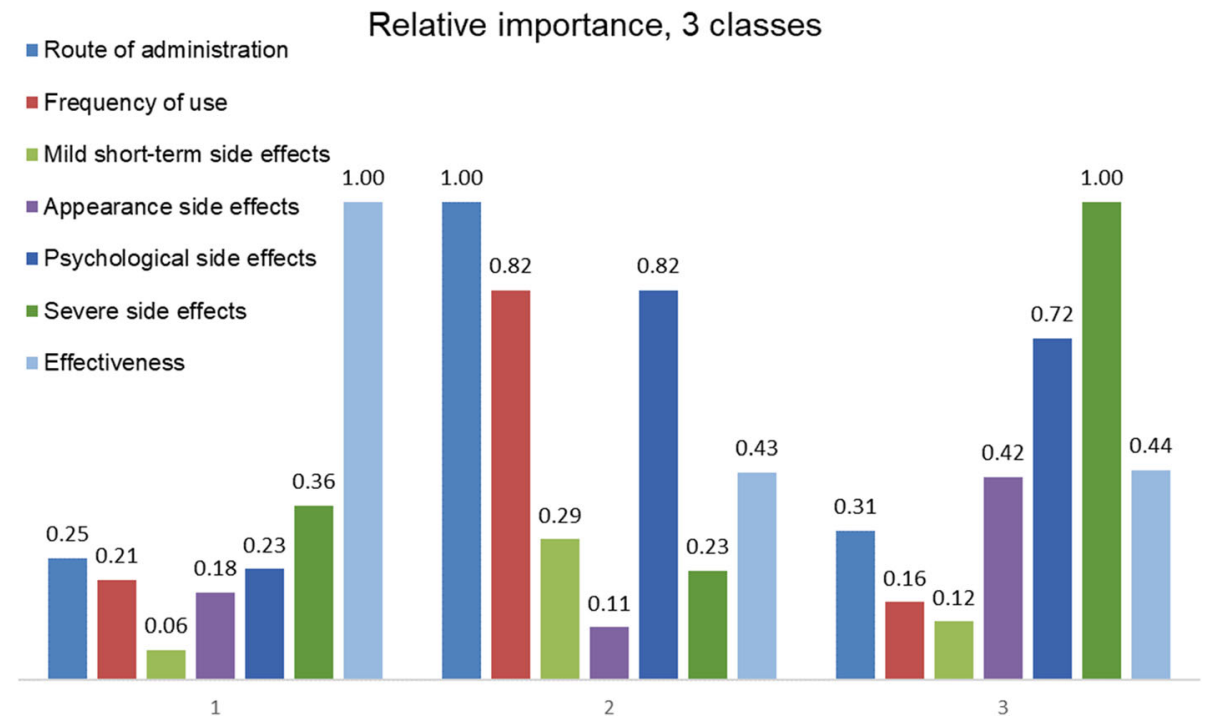

Fig. 2 Relative importance score of attributes

choice questions, such as the probability of psychological side effects or side effects changing appearance and the probabilities of these side effects.

For patients whose choices were most influenced by treatment effectiveness, the impact of side effects on decision-making was marginal. These patients might be recognised as a subgroup with increased willingness to accept higher risk of side effects for an increase in effectiveness. Such patients might be willing to try a new orally administered treatment even though there is uncertainty regarding long-term safety outcomes. Newly diagnosed patients preferred an oral medication over all other attributes; however, they did not accept an increased risk of severe side effects. Similarly, patients with longer disease duration and experience with mild side effects were less willing to accept a treatment with a higher risk of severe side effects.

Previous studies have revealed that rheumatologists and patients with RA have different treatment preferences [14, 31]. This study could support rheumatologists and patients in shared decision-making by identifying which attributes should be the focus of treatment discussions. This study has also revealed the trade-offs that patients with RA are willing to make, a finding that may help patients recognise what is most important from an individual perspective. Tailoring treatment according to

Table 4 Minimum acceptable benefit for changes in attribute levels

\begin{tabular}{|c|c|c|c|c|}
\hline \multirow[t]{2}{*}{ Attribute } & \multirow[t]{2}{*}{ Change } & \multicolumn{3}{|c|}{ Minimum acceptable benefit in percentage } \\
\hline & & Class 1 & Class 2 & Class 3 \\
\hline \multirow[t]{3}{*}{ Probability of mild short-term side effects } & Moving from 0.1 to $10 \%$ & 2.5 & 27.0 & 11.0 \\
\hline & Moving from 0.1 to $1 \%$ & 1.3 & - & 1.5 \\
\hline & Moving from 1 to $10 \%$ & 1.3 & 35.0 & 9.5 \\
\hline \multirow[t]{3}{*}{ Probability of side effects changing appearance } & Moving from 0.1 to $10 \%$ & 7.3 & 34.1 & 38.8 \\
\hline & Moving from 0.1 to $1 \%$ & - & 10.0 & 12.0 \\
\hline & Moving from 1 to $10 \%$ & 7.6 & 24.0 & 26.8 \\
\hline \multirow[t]{3}{*}{ Probability of psychological side effects } & Moving from 0.1 to $10 \%$ & 9.3 & 75.0 & 65.3 \\
\hline & Moving from 0.1 to $1 \%$ & - & 62.0 & 8.5 \\
\hline & Moving from 1 to $10 \%$ & 9.3 & 13.0 & 56.8 \\
\hline \multirow[t]{3}{*}{ Probability of severe side effects } & Moving from 0.1 to $10 \%$ & 14.6 & 21.0 & 91.3 \\
\hline & Moving from 0.1 to $1 \%$ & - & 8.0 & 18.8 \\
\hline & Moving from 1 to $10 \%$ & 21.4 & 13.0 & 71.5 \\
\hline
\end{tabular}


patients' preferences may increase treatment satisfaction and compliance, which could improve treatment outcomes in patients with RA [3].

For regulatory decision-making, considering preference heterogeneity in marketing authorisations or in post authorisations may lead to decisions that are more acceptable to the end users. Treatment satisfaction may increase for patients with a higher acceptance of side effects if the prospect of effectiveness is higher [32, 33].

There are some limitations of this study. First, several sources were used to recruit patients with RA and there was limited control over patient selection, it was not possible to calculate the response rate. However, respondents were only able to participate at one time and no duplicates were found in the patient sample. The patient characteristics (age, gender, education and treatment experience) suggest a representative sample of the Swedish RA population [34]. This article provides a useful addition to the literature by assessing the Swedish population. The results may not be generalizable to other European countries as the health care systems are different. However, there is some concordance between the results of similar, previous studies in a range of countries [35].

Future research should focus on other important disease-related characteristics such as disease activity and risk propensity, characteristics that may influence respondents' preferences. Research needs to develop methods and guidelines to bring in the results of patient preference assessments in both regulatory marketing approval decisions and in the clinical context of shared decision-making.

\section{Conclusions}

Respondents' choices were most influenced by effectiveness of treatment, route of administration or probability of severe side effects. Patients who found effectiveness of treatment to be most important only reported a marginal impact of side effects; these patients might be recognised as a subgroup of patients more willing to accept higher risk of side effects for increased effectiveness. Other patients may not accept a switch associated with increased risk of severe side effects. This study could support personalisation of treatment with secondline treatment by recognising the different preference patterns of patients and the minimum acceptable levels of benefit. Consideration of preference heterogeneity in marketing authorisations or in post authorisations may lead to decisions more acceptable to the end users.

\section{Acknowledgements}

This text and its contents reflect the PREFER project's view and not the view of IMI, the European Union or EFPIA. The authors would like to thank The Swedish Rheumatism Association for their support in the recruitment of patient research partners and participants in the survey. Our sincere gratitude to Marie Almquist and Marie Heidenvall for providing their expertise as patient research partners throughout the research. We also thank Anna Vikerfors from the Swedish Medical Product Agency and members in the PREFER project for reviewing the research process and results.

\section{Authors' contributions}

All authors have made substantial contributions to the conception, design of the work, the analysis and interpretation of data. All authors contributed to drafting of the work and substantively revised it. All authors read and approved the final manuscript.

\section{Funding}

The Patient Preferences in Benefit-Risk Assessments during the Drug Life Cycle (PREFER) is a 5-year project that has received funding from the Innovative Medicines Initiative 2 Joint Undertaking under grant agreement No. 115966. This Joint Undertaking receives support from the European Union's Horizon 2020 research and innovation programme and the European Federation of Pharmaceutical Industries and Associations (EFPIA). KR is supported by the Birmingham NIHR Biomedical Research Centre and is a member of the Research into Inflammatory Arthritis Centre Versus Arthritis and the MRC Versus Arthritis Centre for Musculoskeletal Ageing Research. Open Access funding provided by Uppsala University.

\section{Availability of data and materials}

The datasets during and/or analysed during the current study available from the corresponding author on reasonable request.

\section{Ethics approval and consent to participate}

The study was approved by the regional ethics review board in Uppsala, Sweden (Reg no. 2017/521, 2018/156). All procedures performed in studies involving human participants were in accordance with the ethical standards of the institutional and/or national research committee and with the 1964 Helsinki declaration and its later amendments or comparable ethical standards. Informed consent was obtained from all individual respondents included in the study.

\section{Consent for publication}

All authors of the manuscript have read and agreed to its content and are accountable for all aspects of the accuracy and integrity of the manuscript in accordance with ICMJE criteria.

\section{Competing interests}

KR is supported by the Birmingham NIHR Biomedical Research Centre and is a member of the Research into Inflammatory Arthritis Centre Versus Arthritis and the MRC Versus Arthritis Centre for Musculoskeletal Ageing Research.

\section{Author details}

${ }^{1}$ Centre for Research Ethics \& Bioethics, Department of Public Health and Caring Sciences, Uppsala University, Husargatan 3, Box 564, 75237 Uppsala, Sweden. ${ }^{2}$ Institute of Inflammation and Ageing, University of Birmingham Research Laboratories, Queen Elizabeth Hospital, Birmingham B15 2WB, UK. ${ }^{3}$ Sandwell and West Birmingham Hospitals NHS Trust, Birmingham B18 7QH, UK. ${ }^{4}$ Department of Medical Sciences, Rheumatology, Uppsala University, SE-751 85 Uppsala, Sweden. ${ }^{5}$ Erasmus School of Health Policy \& Management, and Erasmus Choice Modelling Centre, Erasmus University Rotterdam, P.O. Box 1738, 3000, DR, Rotterdam, The Netherlands.

Received: 20 July 2020 Accepted: 9 December 2020

Published online: 19 December 2020

\section{References}

1. Charles C, Gafni A. The vexing problem of defining the meaning, role and measurement of values in treatment decision-making. J Comp Effectiveness Res. 2014;3(2):197-209.

2. Alten R, Kruger K, Rellecke J, Schiffner-Rohe J, Behmer O, Schiffhorst G, Nolting HD. Examining patient preferences in the treatment of rheumatoid arthritis using a discrete-choice approach. Patient Prefer Adherence. 2016;10: 2217-28.

3. Fraenkel L, Nowell WB, Michel G, Wiedmeyer C. Preference phenotypes to facilitate shared decision-making in rheumatoid arthritis. Ann Rheum Dis. 2018;77(5):678-83. https://doi.org/10.1136/annrheumdis-2017-212407. 
4. Augustovski F, Beratarrechea A, Irazola V, Rubinstein F, Tesolin P, Gonzalez J, Lencina V, Scolnik M, Waimann C, Navarta D, et al. Patient preferences for biologic agents in rheumatoid arthritis: a discrete-choice experiment. Value Health. 2013;16(2):385-93.

5. Louder AM, Singh A, Saverno K, Cappelleri JC, Aten AJ, Koenig AS, Pasquale MK. Patient preferences regarding rheumatoid arthritis therapies: a conjoint analysis. Am Health Drug Benefits. 2016;9(2):84-93.

6. Meara A, Crossnohere NL, Bridges JFP. Methods for measuring patient preferences: an update and future directions. Curr Opin Rheumatol. 2019; 31(2):125-31.

7. Patient preference information - voluntary submission, review in premarket approval applications, humanitarian device exemption applications, and de novo requests, and inclusion in decision summaries and device labeling: guidance for industry, food and drug administration staff, and other stakeholders. In., August 24, 2016. edn: U.S. Department of Health and Human Services, Food and Drug Administration, Center for Devices and Radiological Health and Center for Biologics Evaluation and Research; 2016.

8. The patient's voice in the evaluation of medicines. https://www.ema.europa. eu/en/documents/report/report-workshop-patients-voice-evaluationmedicines_en.pdf. European Medicines Agency. Stakeholders and Communication Division. 2013. Report No: 607864.

9. Ho M, Saha A, McCleary KK, Levitan B, Christopher S, Zandlo K, Braithwaite RS, Hauber AB. A framework for incorporating patient preferences regarding benefits and risks into regulatory assessment of medical technologies. Value Health. 2016;19(6):746-50.

10. Muhlbacher AC, Juhnke C, Beyer AR, Garner S. Patient-focused benefit-risk analysis to inform regulatory decisions: the European Union perspective. Value Health. 2016;19(6):734-40.

11. Aletaha D, Smolen JS. Diagnosis and management of rheumatoid arthritis: a review. Jama. 2018;320(13):1360-72

12. European Medicines Agency [http://www.ema.europa.eu/ema/].

13. van Heuckelum M, Mathijssen EG, Vervloet M, Boonen A, Hebing RC, Pasma A, Vonkeman HE, Wenink MH, van den Bemt BJ, van Dijk L. Preferences of patients with rheumatoid arthritis regarding disease-modifying antirheumatic drugs: a discrete choice experiment. Patient Prefer Adherence. 2019;13:1199-211.

14. Nolla JM, Rodriguez M, Martin-Mola E, Raya E, Ibero I, Nocea G, Aragon B, Lizan L, Prades M. Patients' and rheumatologists' preferences for the attributes of biological agents used in the treatment of rheumatic diseases in Spain. Patient Prefer Adherence. 2016;10:1101-13.

15. Clark MD, Determann D, Petrou S, Moro D, de Bekker-Grob EW. Discrete choice experiments in health economics: a review of the literature. Pharmacoeconomics. 2014;32(9):883-902.

16. Ryan M, Gerard K. Using discrete choice experiments to value health care programmes: current practice and future research reflections. Appl Health Economics Health Policy. 2003;2(1):55-64.

17. Viney R, Savage E, Louviere J. Empirical investigation of experimental design properties of discrete choice experiments in health care. Health Econ. 2005; 14(4):349-62.

18. Lancsar E, Louviere J. Conducting discrete choice experiments to inform healthcare decision making: a user's guide. PharmacoEconomics. 2008;26(8): 661-77.

19. Aletaha D, Neogi T, Silman AJ, Funovits J, Felson DT, Bingham CO 3rd Birnbaum NS, Burmester GR, Bykerk VP, Cohen MD, et al. Rheumatoid arthritis classification criteria: an American College of Rheumatology/ European League Against Rheumatism collaborative initiative. Arthritis Rheumatism. 2010;62(9):2569-81.

20. van Tuyl LH, Sadlonova M, Hewlett S, Davis B, Flurey C, Goel N, Gossec L, Heegaard Brahe C, Hill CL, Hoogland W, et al. The patient perspective on absence of disease activity in rheumatoid arthritis: a survey to identify key domains of patient-perceived remission. Ann Rheum Dis. 2017;76(5):855-61.

21. Husni ME, Betts KA, Griffith J, Song Y, Ganguli A. Benefit-risk trade-offs for treatment decisions in moderate-to-severe rheumatoid arthritis: focus on the patient perspective. Rheumatol Int. 2017;37(9):1423-34.

22. Hazlewood GS, Bombardier C, Tomlinson G, Thorne C, Bykerk VP, Thompson A, Tin D, Marshall DA. Treatment preferences of patients with early rheumatoid arthritis: a discrete-choice experiment. Rheumatology (Oxford, England). 2016;55(11):1959-68.

23. van der Elst K, Meyfroidt S, De Cock D, De Groef A, Binnard E, Moons P, Verschueren $\mathrm{P}$, Westhovens R. Unraveling patient-preferred health and treatment outcomes in early rheumatoid arthritis: a longitudinal qualitative study. Arthritis Care Research. 2016;68(9):1278-87.

24. Harrison M, Marra C, Shojania K, Bansback N. Societal preferences for rheumatoid arthritis treatments: evidence from a discrete choice experiment. Rheumatology. 2015;54(10):1816-25.

25. Hiligsmann M, van Durme C, Geusens P, Dellaert BG, Dirksen CD, van der Weijden T, Reginster JY, Boonen A. Nominal group technique to select attributes for discrete choice experiments: an example for drug treatment choice in osteoporosis. Patient Preference Adherence. 2013;7:133-9.

26. Wangdahl JM, Martensson LI. The communicative and critical health literacy scale--Swedish version. Scand J Public Health. 2014:42(1):25-31.

27. McNaughton CD, Cavanaugh KL, Kripalani S, Rothman RL, Wallston KA. Validation of a short, 3-item version of the Subjective Numeracy Scale. Med Decision Making. 2015;35(8):932-6.

28. Bridges JF, Hauber AB, Marshall D, Lloyd A, Prosser LA, Regier DA, Johnson FR, Mauskopf J. Conjoint analysis applications in health--a checklist: a report of the ISPOR Good Research Practices for Conjoint Analysis Task Force. Value Health. 2011;14(4):403-13.

29. Swait J, Louviere J. The role of the scale parameter in the estimation and comparison of multinomial logit models. J Mark Res. 1993;30(3):305-14.

30. Zhou M, Thayer WM, Bridges JFP. Using latent class analysis to model preference heterogeneity in health: a systematic review. Pharmacoeconomics. 2018;36(2):175-87.

31. Scalone L, Sarzi-Puttini P, Sinigaglia L, Montecucco C, Giacomelli R, Lapadula G, Olivieri I, Giardino AM, Cortesi PA, Mantovani LG, et al. Patients', physicians', nurses', and pharmacists' preferences on the characteristics of biologic agents used in the treatment of rheumatic diseases. Patient Prefer Adherence. 2018;12:2153-68.

32. Johnson FR, Beusterien K, Ozdemir S, Wilson L. Giving patients a meaningful voice in United States regulatory decision making: the role for health preference research. Patient. 2017;10(4):523-6.

33. Hsiao B, Binder-Finnema P, Benjamin Nowell W, Michel G, Wiedmeyer C, Fraenkel L. Preference phenotypes can be used to support shared decisionmaking at point-of-care for patients with rheumatoid arthritis: A proof of concept study. Arthritis care \& research. 2018. https://doi.org/10.1002/acr. 23684.

34. Eriksson JK, Neovius M, Ernestam S, Lindblad S, Simard JF, Askling J. Incidence of rheumatoid arthritis in Sweden: a nationwide populationbased assessment of incidence, its determinants, and treatment penetration. Arthritis Care Research. 2013;65(6):870-8.

35. Durand C, Eldoma M, Marshall DA, Bansback N, Hazlewood GS. Patient preferences for disease-modifying antirheumatic drug treatment in rheumatoid arthritis: a systematic review. J Rheumatol. 2020;47(2):176-87.

\section{Publisher's Note}

Springer Nature remains neutral with regard to jurisdictional claims in published maps and institutional affiliations.

\section{Ready to submit your research? Choose BMC and benefit from:}

- fast, convenient online submission

- thorough peer review by experienced researchers in your field

- rapid publication on acceptance

- support for research data, including large and complex data types

- gold Open Access which fosters wider collaboration and increased citations

- maximum visibility for your research: over $100 \mathrm{M}$ website views per year

At BMC, research is always in progress.

Learn more biomedcentral.com/submissions 